\title{
The effect of non-restorative treatments on the progression of artificial dentine caries lesions underneath enamel
}

Tamires Timm Maske ${ }^{a}$, Camila Neunfeldt Nascimento $^{a}$, Françoise Hélène van de Sande ${ }^{a}$, Marina Sousa Azevedo ${ }^{a}$, Elenara Ferreira Oliveira ${ }^{a}$, Maximiliano Sérgio Cenci ${ }^{\mathrm{a}}$

\section{Abstract}

Objective: To develop an experimental model for hidden caries lesions and to evaluate the effect of $0.12 \%$ chlorhexidine (CHX) and $1.23 \%$ acidulated phosphate fluoride (APF) on biofilm formation and on the dentine demineralization.

Methods: Dentine discs with artificial lesions were divided into four subgroups (500-100-0 $\mu \mathrm{m}$ gaps or sound enamel). Enamel discs were adapted over the dentine samples and fixed in acetate matrices. Microcosm biofilms were formed on the specimens for 10 days (cariogenic condition). Specimens from subgroups $(n=9)$ were individually treated for 1 min by daily immersion in $\mathrm{CHX}$ or saline, or weekly in APF suspension. Biofilms were quantified [total microorganism (TM) and mutans streptococci (MS)]. Mineral profiles were assessed by Transverse Microradiography. Data were analyzed by ANOVA, Holm-sidak and paired t-test $(p<0.05)$

Results: CHX decreased MT counts and increased MS counts compared to other treatments in gaps presence or absence $(p<0.05)$. For the control, $500 \mu \mathrm{m}$ gap caused higher TM counts $(p=0.024)$. No significant differences (treatment groups $\times$ subgroups) were found for the mineral profiles. Conclusion: $500 \mu \mathrm{m}$ gap does not generate higher microbial colonization and $\mathrm{CHX}$ does not inhibit MS colonization of surfaces. APF and CHX showed positive trend for lesions remineralization.

Key words: Biofim; hidden caries; fluoride; chlorhexidine; demineralization

\section{O efeito de tratamentos não restauradores na progressão de lesões artificiais de cárie dentinária sob esmalte}

\section{Resumo}

Objetivo: Desenvolver um modelo experimental para avaliar o efeito da clorexidina $0,12 \%(\mathrm{CHX})$ e flúor fosfato acidulado 1,23\% (APF) na formação de biofilme e desmineralização da dentina em lesões de cárie ocultas. Métodos: Discos de dentina com lesões artificiais foram divididos em gaps com 500-100-0 $\mu$ m ou esmalte hígido). Discos de esmalte foram adaptados sobre as amostras de dentina e fixados em matrizes de acetato. Biofilmes microcosmos foram formados sobre as amostras durante 10 dias sob desafio cariogênico. Espécimes de subgrupos $(n=9)$ foram tratados durante 1 min por imersão diária em $\mathrm{CHX}$ ou soro fisiológico, ou semanalmente, em suspensão APF. Biofilmes foram quantificados [microorganismo total (MT) e estreptococos mutans (MS)]. Perfis minerais foram avaliados por microradiografia Transversal. Analisou-se os dados por ANOVA, Holm-Sidak e teste t pareado $(p<0,05)$.

Resultados: CHX diminui a contagem de MT e aumentou a contagem de EM em comparação a outros tratamentos em presença ou ausência de gaps $(p<0,05)$. No grupo controle, gaps de $500 \mu \mathrm{m}$ causaram maiores contagens de TM $(p=0,024)$. Não houve diferença (tratamento $X$ gaps) para os perfis minerais

Conclusão: Gaps de $500 \mu \mathrm{m}$ não geram maior colonização microbiana e CHX não inibiu a colonização de $\mathrm{MS}$. APF e CHX mostram tendência positiva para a remineralização de lesões.

Palavras-chave: Biofilme; cárie oculta; flúor; clorexidina; desmineralização a Graduate Program in Dentistry, Federal University of Pelotas, Pelotas, Brazil.
Correspondence: Maximiliano Sérgio Ceno m.s.cenci@pq.cnpq.br / cencims@gmail.com

Received: December 6, 2012 Accepted: November 5, 2014

Conflict of Interests: The authors state that there are no financial and personal conflicts of interest that could have inappropriately influenced their work

Copyright: (c) 2014 Maske et al licensee EDIPUCRS

Except where otherwise noted, content of this journal is licensed under a Creative Commons Attribution 4.0 isternational license. 


\section{Introduction}

Epidemiological studies have shown that due to the reduction of caries incidence, most lesions that still occur are located on the occlusal surface [1-3]. Some of these lesions have a difficult diagnosis since they show clinically sound or minimally demineralized occlusal enamel, but show extensive radiographic demineralization in dentine. These lesions are usually denominated as "hidden caries lesions" [4-6].

When hidden caries lesions are detected, restorative treatment has been recommended and the use of sealants or removal of the infected dentine associated with conventional restoration has been reported [5,7]. However, other less invasive and less expensive alternatives are poorly investigated as options of treatment for these lesions. Also, appropriate models to simulate and to study treatment options for occlusal hidden caries lesions are missing in the current literature. In vitro microcosm biofilms have been proposed to test different hypothesis in dentistry [8-10], and could be useful to simulate clinical conditions related to the development of caries.

It is known that fluoride and chlorhexidine are anti-caries agents and play an important role in the prevention of dental caries. Fluoride has an important effect on the inhibition of demineralization and on activating the remineralization of tooth structures. Chlorhexidine is able to act on the bacterial metabolism and suppress the growth of total microorganisms and mutans streptococci $[11,12]$. Moreover, some studies have demonstrated that $\mathrm{CHX}$ could also inhibit the activity of dentine matrix metalloproteinases (MMPs) [13], suggesting that it could help to prevent dentine demineralization [14].

Non-invasive therapies could be useful in the treatment of occlusal caries, especially for lesions limited to the outer dentine layer. The general aim of this study was to develop an experimental model simulating occlusal hidden caries. Specific aims were to evaluate the biofilm modifications and the dentine de/remineralization response to cariogenic conditions with different enamel conditions and under different therapies.

\section{Methods}

\section{Study set-up}

Biofilms were formed in 24 microwell plates from human saliva inoculum on the specimens. The dentine specimens with artificial caries-like lesions were divided into four subgroups according to simulated occlusal gaps (500, 100, $0 \mu \mathrm{m}$ and sound enamel) and a defined medium enriched with mucin (DMM) [15] supplemented with 1\% sucrose under an intermittent regimen was used to grow the biofilms [8]. Biofilms were grown anaerobically at $37^{\circ} \mathrm{C}$ for 10 days. Specimens of the subgroups (presence of gap X treatment, $\mathrm{n}=9$ ) were individually treated by daily immersion in chlorhexidine or saline (control), or were weekly immersion in a suspension of APF. Treatments were applied for $1 \mathrm{~min}$ before challenges with sucrose (Fig. 1). The results were obtained by quantification of total microrganisms (TM) and mutans streptococci (MS) performed through the collection of biofilms $24 \mathrm{~h}$ after the last treatment. Next, lesion depth and mineral loss were assessed by transverse microradiography.

\section{Preparation of samples}

One hundred and eight bovine teeth were selected and cut at the buccal surface with a water-cooled trephine drill. After obtaining standardized discs of approximately $4 \mathrm{~mm}$ in thickness and $6 \mathrm{~mm}$ in diameter, they were sectioned with a water-cooled diamond saw at the dentine-enamel junction in order to obtain separate discs of dentine and enamel.

All surfaces of the dentine discs were covered with nail varnish, except for a $2 \mathrm{~mm}^{2}$ window on the top surface. The discs were autoclaved and the exposed area was subjected to constant cariogenic challenge through immersion in BHI broth with $1 \%$ sucrose, inoculated with mutans streptococci (UA 159) at $37^{\circ} \mathrm{C}$ and in anaerobic condition for 7 days. The broth was replaced daily. After lesion development, 1/3 of these baseline lesions were protected with nail varnish in order to enable paired evaluations from the mineral dentine profiles before and after the subsequent cariogenic challenge and treatments in the biofilm model.

The dentine discs were divided into four groups according to the enamel condition: sound enamel, enamel with 500,100, and $0 \mu \mathrm{m}$ simulated gaps. Enamel discs with no gap are referred here as sound enamel, whereas $0 \mu \mathrm{m}$ gap was used to refer to juxtaposed enamel halves with no visible gap. Enamel discs or half-discs were then adapted over the dentine with wax, simulating enamel gaps with communication with the underlying dentine. The samples were sterilized by gamma radiation.

\section{Inoculation procedure and microcosm growth}

After approval by the Local Ethics Research Committee (Protocol \#228/2011), $20 \mathrm{ml}$ of stimulated saliva by paraffin film were collected from a healthy volunteer (female, 22 years old), who had not received antibiotic therapy for a year and had abstained from oral hygiene for $24 \mathrm{~h}$ as well as from food ingestion for $2 \mathrm{~h}$ prior to collection.

The saliva was inoculated on the specimens $(400 \mu \mathrm{l}$ for each) in plates of 24 micro-wells. After $1 \mathrm{~h}$ rest at $37^{\circ} \mathrm{C}$, the saliva was gently aspirated from the bottom of the wells, $1.8 \mathrm{ml}$ of medium (DMM) with $1 \%$ sucrose were added to each well and the plates were incubated at $37^{\circ} \mathrm{C}$, under anaerobic atmosphere. After $6 \mathrm{~h}$, the specimens were rinsed through immersion in $2 \mathrm{ml}$ of sterile saline, inserted into a new plate containing pure DMM and incubated for $18 \mathrm{~h}$, under the same conditions. Biofilms were formed individually on the specimens in each well, for up to 10 days, on which the same routine of alternate exposure to DMM supplemented with sucrose or pure was followed, as described previously [8, 10].

\section{Treatment}

The treatments were carried out through immersion for $1 \mathrm{~min}$ before the challenges with sucrose. For the groups 


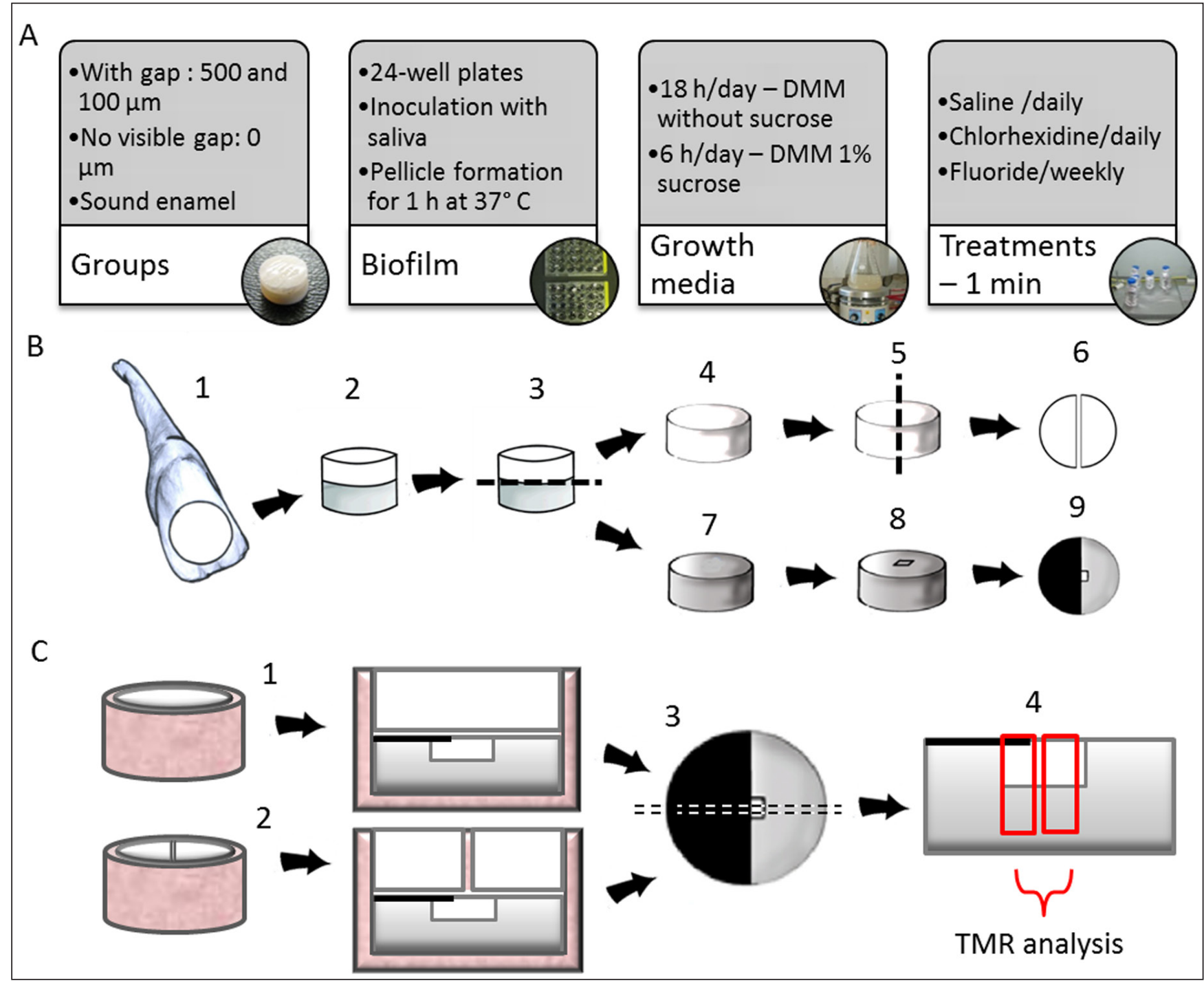

Fig 1. A) Schematic representation of study design. B) Preparation of dentine and enamel discs. 1. Bovine incisors teeth cut at the labial surface. 2. Standardized discs of approximately $4 \mathrm{~mm}$ in thickness and $6 \mathrm{~mm}$ in diameter. 3. Discs were sectioned with a water-cooled diamond at the dentine-enamel junction. 4. Sound enamel disc. $\mathbf{5}$ and $\mathbf{6}$. Enamel disc sectioned into halves. 7. Dentine disc. 8. Dentine discs covered with nail varnish, except for a $2 \mathrm{~mm}^{2}$ area. 9. After baseline lesion formation (mutans streptococci and cariogenic challenge), 1/3 of the lesion was covered with nail varnish-protected area. C) Schematic structure of the specimens. 1. Sample with sound enamel. 2. Sample with gap. 3. Dentine specimens sectioned across the reference landmarks of the lesion and 4 . slices of $300 \mu \mathrm{m}$ were prepared for TMR analysis.

treated with $0.12 \%$ chlorhexidine and saline (control), treatments were applied once a day, whereas for the group treated with $1.23 \%$ acidulated phosphate fluoride, it was once a week (total of two treatments).

\section{Biofilm microbial composition}

After the trial period (10 days), fifty-four specimens ( $500 \mu \mathrm{m}$ and sound enamel) were transferred to tubes containing $1 \mathrm{ml}$ of $0.9 \% \mathrm{NaCl}$. The biofilms were dispersed and homogenised by sonication at $20 \mathrm{w}$ for $30 \mathrm{~s}$, serially diluted in concentrations up to $10^{-7}$, and plated in duplicate on Blood Agar and Mitis Salivarius Agar with Bacitracin. The plates were incubated anaerobically at $37^{\circ} \mathrm{C}$ for $96 \mathrm{~h}$ for analysis of microbial growth. To determine the biofilm dry weight, aliquots of $200 \mu \mathrm{L}$ of the initial biofilm suspension were transferred to pre-weighted tubes, and dehydrated with ethanol solutions $(99 \%$ and $75 \%)$. Then, the tubes were centrifuged, the supernatants were discarded, and the pellet was dried under a desiccator $\left(\mathrm{P}_{2} \mathrm{O}_{5}\right)$ for $48 \mathrm{~h}$ and weighted. The biofilm dry weight was determined by calculating the weight in the tube (final weigh - initial weight) and the original suspension (dry weight in $1 \mathrm{~mL}=$ dry weight in $200 \mu \mathrm{L} \times 5$ ). The colony-forming units (CFU) were counted and the results expressed in CFU/mg biofilm (dry weight).

\section{Analysis of lesion depth and mineral loss}

After the trial period the samples were cleaned with water and a soft bristle toothbrush and separated into enamel 
and dentine discs. The dentine specimens were precisely sectioned across the reference landmarks of the lesion with a water-cooled diamond disc, hand-polished with carbidepaper until reaching a uniform thickness of $300 \mu \mathrm{m}$. The slices were coupled on a plastic matrix and radiographs were taken on high-resolution plates (Fuji B\&W POS/71337) with an $\mathrm{x}$-ray source operating at $60 \mathrm{kV}$ and $30 \mathrm{~mA}$ for $8 \mathrm{~s}$. The radiographs were scanned as images through a camera (Canon EOS 50D, DS 126211, Canon Inc., Japan) attached to a stereomicroscope (Stereomicroscope M50, Model/PNMDG33/10450123, Leica, Singapore). The mineral profiles were plotted in two regions of interest (protected and not protected area). The image-analysis referring to lesion depth $[(\mathrm{LD}) \mu \mathrm{m}]$ and mineral loss $[\Delta \mathrm{Z}(\mathrm{vol} \% \mu \mathrm{m})]$ were done using the TeeChart 8 software.

\section{Statistical analysis}

Data analysis was performed with SigmaStat v. 3.5 statistical software (Systat Inc., USA). Microbiological data were analysed by ANOVA and Holm-Sidak, and mineral profile data were analysed by subtracting mineral loss and lesion depth outcomes for protected areas from those of non-protected areas for each samples, yielding the de- or remineralization during the experimental period. Single group T-tests were performed to evaluate significant changes. ANOVA and Holm-Sidak analyses were used to evaluate effects of treatments and gap status. The significance level was set at $5 \%$.

\section{Results}

The results for the microradiographic analysis are shown in Tables 1 and 2. The changes in both mineral loss and lesion depth during the treatment period were not significant for any of the groups. No statistically significant differences were found in the comparison among treatments or gap sizes (enamel condition) for mineral loss or lesion depth.

Microbiological data demonstrated that chlorhexidine decreased the counts of total microrganism (TM) when compared with other treatments, irrespective of the presence or absence of gaps $(\mathrm{p}<0.05)$. The data also showed that the presence of large gaps caused higher TM counts only for the control group $(\mathrm{p}=0.024)$. Also, $\mathrm{CHX}$ generated higher counts of MS in relation to other treatments $(\mathrm{p}=0.026)$ (Figure 2 and 3 ).

Table 1. $\Delta Z$ (vol\% $\mu \mathrm{m})$ analysed in the protected (baseline caries lesions) and not protected area after treatments

\begin{tabular}{|c|c|c|c|c|c|c|}
\hline \multirow{2}{*}{ Enamel condition } & \multicolumn{2}{|c|}{ Chlorhexidine } & \multicolumn{2}{|c|}{ Fluoride } & \multicolumn{2}{|c|}{ Saline } \\
\hline & Protected & No protected & Protected & No protected & Protected & No protected \\
\hline $500 \mu \mathrm{m}$ & $\begin{array}{l}10385.4 \\
(1790.0)\end{array}$ & $\begin{array}{c}9851.4 \\
(2818.6)\end{array}$ & $\begin{array}{c}7037.6 \\
(3315.1)\end{array}$ & $\begin{array}{c}6955.1 \\
(3829.3)\end{array}$ & $\begin{array}{c}7907.6 \\
(1948.2)\end{array}$ & $\begin{array}{c}8525.4 \\
(2569.7)\end{array}$ \\
\hline $100 \mu \mathrm{m}$ & $\begin{array}{c}8333.8 \\
(3661.9)\end{array}$ & $\begin{array}{c}9983.6 \\
(4759.4)\end{array}$ & $\begin{array}{l}10500.6 \\
(3081.1)\end{array}$ & $\begin{array}{l}11096.3 \\
(3566.1)\end{array}$ & $\begin{array}{c}8049.9 \\
(2947.9)\end{array}$ & $\begin{array}{c}8814.7 \\
(3860.9)\end{array}$ \\
\hline $0 \mu \mathrm{m}$ & $\begin{array}{c}8279.0 \\
(3771.9)\end{array}$ & $\begin{array}{c}8878.9 \\
(5742.0)\end{array}$ & $\begin{array}{c}8752.2 \\
(4158.6)\end{array}$ & $\begin{array}{c}9170.1 \\
(4751.3)\end{array}$ & $\begin{array}{c}7926.8 \\
(3512.2)\end{array}$ & $\begin{array}{c}9461.7 \\
(4895.1)\end{array}$ \\
\hline Sound & $\begin{array}{c}7901.2 \\
(3622.6)\end{array}$ & $\begin{array}{c}8422.4 \\
(4141.3)\end{array}$ & $\begin{array}{c}6899.3 \\
(3372.1)\end{array}$ & $\begin{array}{c}6941.0 \\
(3366.7)\end{array}$ & $\begin{array}{c}9074.8 \\
(3368.2)\end{array}$ & $\begin{array}{c}9126.6 \\
(3981.2)\end{array}$ \\
\hline
\end{tabular}

Note: Data are given are means (SD); There were not statistically significant differences (Paired T-test, $p>0.05$ ).

Table 2. LD $(\mu \mathrm{m})$ analysed in the protected (baseline caries lesions) and not protected area after treatments

\begin{tabular}{|c|c|c|c|c|c|c|}
\hline \multirow{2}{*}{ Enamel condition } & \multicolumn{2}{|c|}{ Chlorhexidine } & \multicolumn{2}{|c|}{ Fluoride } & \multicolumn{2}{|c|}{ Saline } \\
\hline & Protected & No protected & Protected & No protected & Protected & No protected \\
\hline $500 \mu \mathrm{m}$ & $\begin{array}{l}393.6 \\
(89.1)\end{array}$ & $\begin{array}{l}370.5 \\
(57.6)\end{array}$ & $\begin{array}{c}320.8 \\
(110.3)\end{array}$ & $\begin{array}{c}287.5 \\
(102.5)\end{array}$ & $\begin{array}{c}341.1 \\
(114.1)\end{array}$ & $\begin{array}{l}311.5 \\
(73.4)\end{array}$ \\
\hline $100 \mu \mathrm{m}$ & $\begin{array}{l}308.9 \\
(90.3)\end{array}$ & $\begin{array}{c}383.9 \\
(139.4)\end{array}$ & $\begin{array}{l}344.5 \\
(98.5)\end{array}$ & $\begin{array}{c}347.0 \\
(102.6)\end{array}$ & $\begin{array}{c}353.2 \\
(118.1)\end{array}$ & $\begin{array}{c}400.8 \\
(154.0)\end{array}$ \\
\hline Sound & $\begin{array}{l}281.0 \\
(86.3)\end{array}$ & $\begin{array}{c}322.9 \\
(154.2)\end{array}$ & $\begin{array}{c}286.5 \\
(127.5)\end{array}$ & $\begin{array}{c}278.6 \\
(111.4)\end{array}$ & $\begin{array}{l}349.3 \\
(83.7)\end{array}$ & $\begin{array}{l}338.2 \\
(68.6)\end{array}$ \\
\hline
\end{tabular}

Note: Data are means (SD); There were no statistically significant differences betwenn protected and not protected dentine (Paired T-test, $p>0.05)$. 


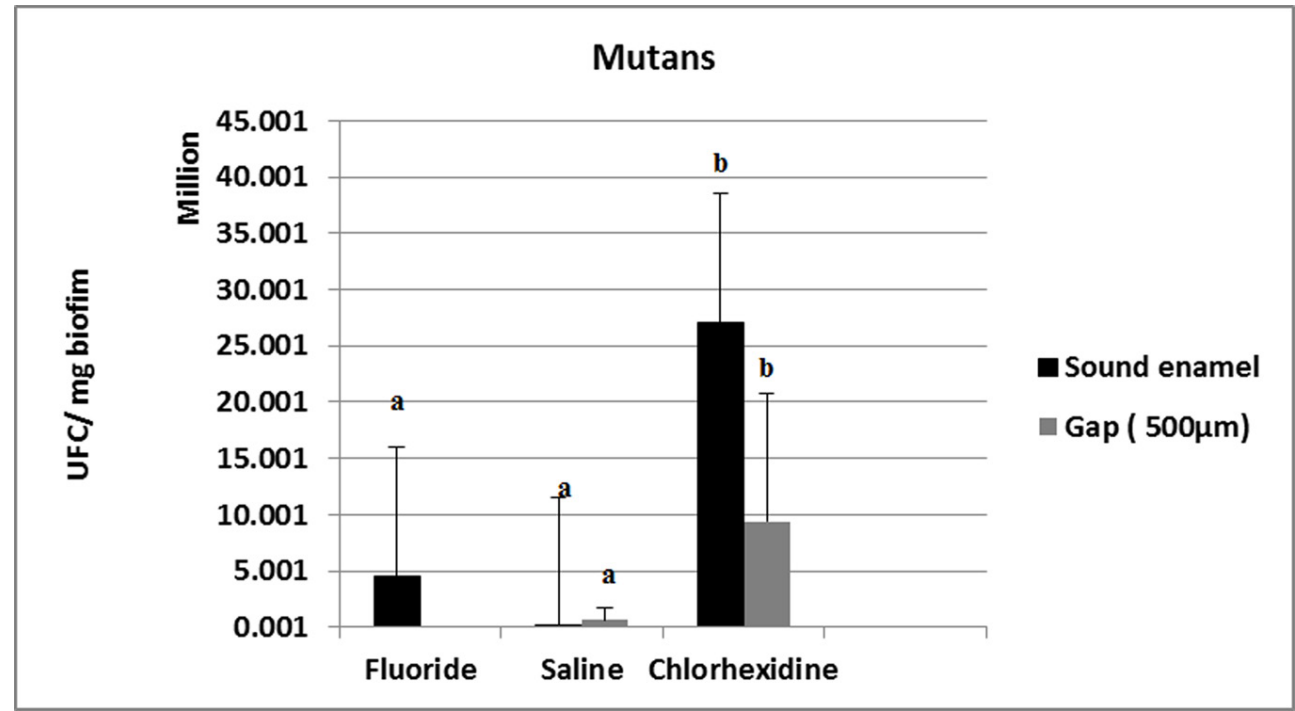

Fig 2. Avarage(SD) score of mutans streptococci after 10 days of growing in artificial saliva. Different lower case letters indicate statistical difference between the averages of the treatment fixing the condition of enamel. (ANOVA followed by Holm-Sidak test $\mathrm{p}<0.05$ ).

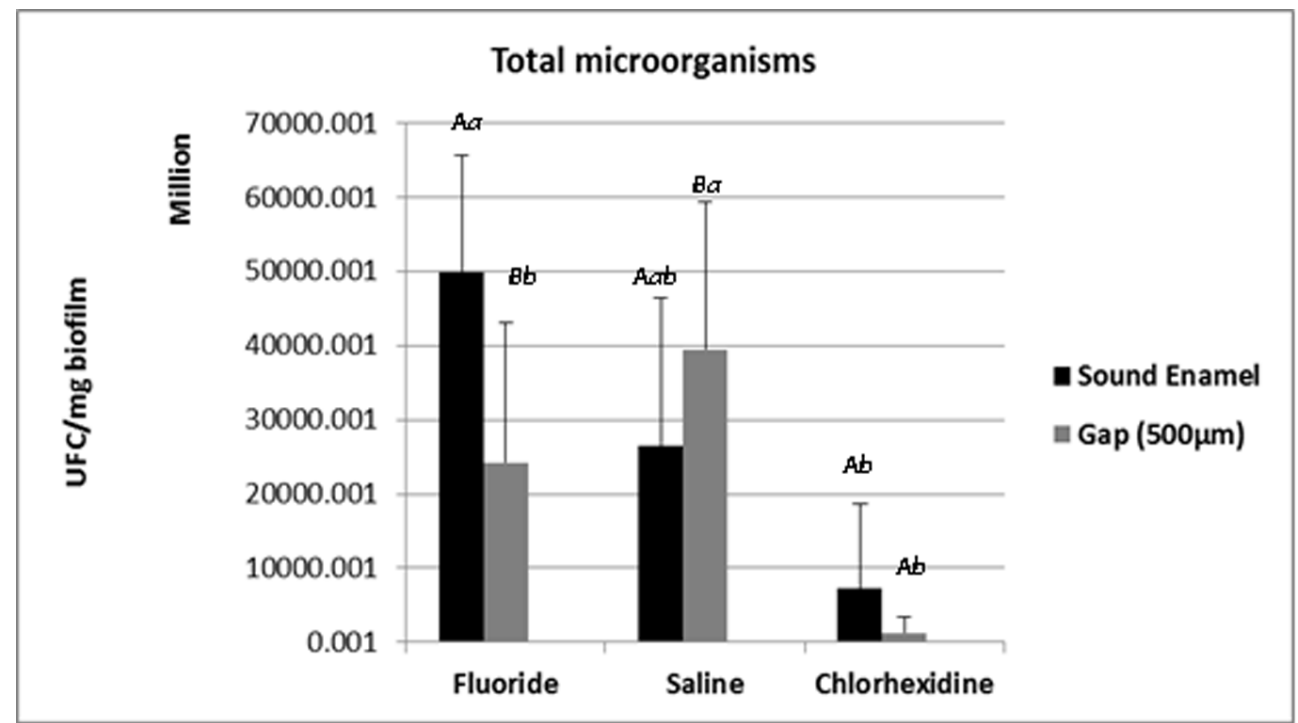

Figure 3. Average (SD) score of Total microorganisms after 10 days of growing in artificial saliva. Different lowercase letters indicate statistically significant difference between the averages of the treatment fixing the enamel condition. Different upper letters indicate statistically significant difference between the two conditions of enamel fixing the treatment condition. (ANOVA followed by Holm-Sidak test $p<0.05$ ).

\section{Discussion}

Our study has shown a promising model to test hypotheses related to the etiopathogenesis and treatment of hidden caries lesions. Some tendencies were observed, as in specimens where narrower fissures were simulated $(100 \mu \mathrm{m}$ or $0 \mu \mathrm{m})$. After treatment with fluoride, narrower fissures showed higher mineral loss and lesion depth in the final lesions (unprotected) than in the protected ones. The stagnation of plaque inside the fissure may be related to this phenomenon, since it would make the diffusion of substances to the dentine region underneath the enamel more difficult. Besides, as described by Zaura et al. [16], the presence of fluoride could make the superficial enamel become fluoride-enriched and less soluble in the acid environment, which could cause superficial buffering of the acid produced and, at the same time, provide a diffusion of acids towards the groove, generating a high cariogenic challenge at the groove bottom and the consequent demineralization of the dentine. Also, the ions that are released during demineralization of dentine 
could contribute to buffering the acids at the enamel level. This was also demonstrated by the decrease of $\mathrm{pH}$ found inside narrow grooves by Zaura et al. [17]. Data found in that study and the ideas cited above complement the rationale developed by Ricketts et al. [5] about the phenomena that would lead to the formation of hidden caries.

In contrast, the presence of wide fissures $(500 \mu \mathrm{m})$ associated to the use of APF weekly would allow the direct diffusion of the treatment to the lesions located in the dentine underneath the enamel, reducing mineral loss and promoting remineralization, a tendency observed in this study. It is believed that the presence of a wider area at the entrance of the fissure would allow greater fluoride diffusion into it, because previous studies have shown that the effectiveness of fluoride from toothpaste in places which present plaque retention depends on the accessibility of each location, with fluoride being less effective in narrower fissures than in wide ones $[18,19]$.

The data on mineral loss regarding the treatment with saline solution also corroborate the tendency of this model, since in the presence of fissures $(500 \mu \mathrm{m}$ or $100 \mu \mathrm{m})$ there was a higher mineral loss in the region exposed to (not protected from) the new cariogenic challenge promoted by the biofilm. However, one limitation of this study is that longer periods of exposure to the cariogenic challenge would be necessary to elucidate the effects of treatments with APF or $\mathrm{CHX}$, especially considering the difficulty of diffusion of the treatments and substrates through the fissures simulated in this model of study.

After the treatment, the count of MS was higher for CHX when compared to other groups. The most accepted explanation for its lower effect on MS and their consequent reappearance is the recolonization of the microorganisms, probably because the reservoirs and retention sites in the dentition are not sufficiently reached due to the low bioavailability of CHX [12]. Clinical studies show that after a treatment with $\mathrm{CHX}$ there is an initial decrease in the presence of MS, but after some time the ecological conditions of the environment favor the recolonization of the dental surfaces by these microrganisms, which may have occurred in this study [20].

In vitro experiments have shown that Streptococcus mutans, microorganism predominantly involved in the development of carious lesions, are responsible only for demineralization of the dentin surface and is unable to degrade dentin matrix $[21,22]$. This fact coupled with the action of CHX in acting as potent inhibitor of MMPs [13], to corroborate the data presented in this study that in wide gaps, CHX limited the degradation of collagen and was responsible for the lower values in lesion depth and mineral loss.

Although this study did not show statistically significant differences among the tested groups considering mineral loss and the depth of caries lesions, it can be inferred that the use of fluoride and chlorexidine generated a positive tendency towards the remineralization of hidden caries lesions, in the presence of wide fissures, whereas which narrow fissures it was not found. However, further studies using this kind of model should be conducted in order to test this correlation, with an extension of the length of the cariogenic challenge and in order to verify the effects of CHX and other treatment options on the control of hidden caries.

\section{Acknowledgments}

The authors wish to thank the Radboud University Nijmegen Medical Center for his valuable contribution in the execution to this study.

\section{References}

1. Pitts NB, Davies JA. The Scottish Health Boards' Dental Epidemiological Programme: initial surveys of 5- and 12-year-olds. Br Dent J. 1992;172: 408-13

2. Macek MD, Beltran-Aguilar ED, Lockwood SA, Malvitz DM. Updated comparison of the caries susceptibility of various morphological types of. J Public Health Dent. 2003;63:174-82.

3. Demirci M, Tuncer S, Yuceokur AA. Prevalence of caries on individual tooth surfaces and its distribution by age and. Eur J Dent. 2010l;4:270-9.

4. Weerheijm KL, Gruythuysen RJ, van Amerongen WE. Prevalence of hidden caries. ASDC J Dent Child. 1992;59:408-12.

5. Ricketts D, Kidd E, Weerheijm K, de Soet H. Hidden caries: what is it? Does it exist? Does it matter? Int Dent J. 1997;47:259-65.

6. Kidd EA, Naylor MN, Wilson RF. Prevalence of clinically undetected and untreated molar occlusal dentine caries in adolescents on the Isle of Wight. Caries Res. 1992;26:397-401.

7. Ricketts DN, Kidd EA, Beighton D. Operative and microbiological validation of visual, radiographic and electronic diagnosis of occlusal caries in non-cavitated teeth judged to be in need of operative care. $\mathrm{Br}$ Dent J. 1995;179:214-20.

8. van de Sande FH, Azevedo MS, Lund RG, Huysmans MC, Cenci MS An in vitro biofilm model for enamel demineralization and antimicrobial dose-response studies. Biofouling. 2011;27:1057-63.

9. Filoche SK, Soma KJ, Sissons $\mathrm{CH}$. Caries-related plaque microcosm biofilms developed in microplates. Oral Microbiol Immunol. 2007;22:73-9.

10. Azevedo MS, van de Sande FH, Romano AR, Cenci MS. Microcosm biofilms originating from children with different caries experience have similar cariogenicity under successive sucrose challenges. Caries Res. 2011;45:510-7.

11. van Rijkom HM, Truin GJ, van 't Hof MA. A meta-analysis of clinical studies on the caries-inhibiting effect of chlorhexidine treatment. J Dent Res. 1996; $75: 790-5$

12. Emilson CG. Potential efficacy of chlorhexidine against mutans streptococci and human dental caries. J Dent Res. $1994 ; 73: 682-91$

13. Toledano M, Yamauti M, Osorio E, Osorio R. Zinc-inhibited MMP-mediated collagen degradation after different dentine demineralization procedures. Caries Res. 2012;46: 201-7

14. Chaussain-Miller C, Fioretti F, Goldberg M, Menashi S. The role of matrix metalloproteinases (MMPs) in human caries. J Dent Res. 2006;85:22-32.

15. Wong $L$, Sissons $C$. A comparison of human dental plaque microcosm biofilms grown in an undefined medium and a chemically defined artificial saliva. Arch Oral Biol. 2001;46: 477-86.

16. Zaura E, van Loveren C, ten Cate JM. Efficacy of fluoride toothpaste in preventing demineralization of smooth dentin surfaces and narrow grooves in situ under frequent exposures to sucrose or bananas. Caries Res. 2005;39:116-22

17. Zaura E, Buijs MJ, ten Cate JM. The effects of the solubility of artificial fissures on plaque pH. J Dent Res. 2002; 81:567-71.

18. Lagerweij MD, Damen JJ, ten Cate JM. Effect of a fluoridated toothpaste on lesion development in plaque-filled dentine grooves: an intra-oral study. Caries Res. 1997;31:141-7.

19. Lagerweij MD, Damen JJ, ten Cate JM. The effect of a fluoridated toothpaste on dentinal lesions in plaque-filled grooves: an intra-oral crossover study. J Dent Res. 1996;75:1687-91.

20. Skold-Larsson K, Sollenius O, Petersson LG, Twetman S. Effect of topical applications of a novel chlorhexidine-thymol varnish formula on mutans streptococci and caries development in occlusal fissures of permanent molars. J Clin Dent. 2009;20:223-6.

21. Katz S, Park KK, Palenik CJ. In-vitro root surface caries studies. J Oral Med. 1987;42:40-8.

22. Hannas AR, Pereira JC, Granjeiro JM, Tjaderhane L. The role of matrix metalloproteinases in the oral environment. Acta Odontol Scand. 2007 65:1-13. 